\title{
THE EFFECT OF DOWEL SPACING ON THE STRESS AND STRAIN OF CASE-TYPE FURNITURE CORNER JOINT
}

\author{
Seid Hajdarević, Sandra Martinović \\ University of Sarajevo, Mechanical Engineering Faculty, Vilsonovo setaliste 9, Sarajevo 71000, \\ Bosnia and Herzegovina
}

\begin{abstract}
This paper presents stress and strain analysis of double-dowel case-type furniture corner joint. Numerical calculations are carried out with a linear elastic model for orthotropic material. The mathematical model is solved by a finite element method. The von Mises stress and displacement are calculated for the simple state of load of MDF board structure. Three dowel spacing are used in order to evaluate the effect of the distance between the centers of dowel holes. The results show that the dowel spacing and the distance between the dowel and the board edge have a considerable impact on the stress state of the face and edge member. Stress patterns obtained in planes of boards show that stress is increased in the areas of fracture zones that occur during the fracture moment tests of dowel joints. Results of the displacement calculation indicate that joint becomes stiffer when the distances between the dowels and the dowel and the board edge are rationally defined.
\end{abstract}

Keyword: case-type furniture; dowel spacing; MDF; numerical analysis; stress and strain
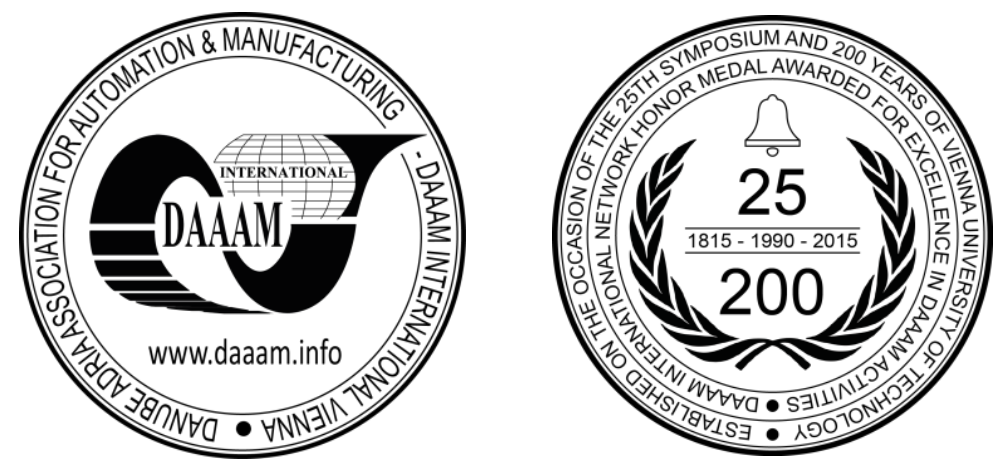

This Publication has to be referred as: Hajdarevic, S[eid] \& Martinovic, S[andra] (2016). The Effect of Dowel Spacing on the Stress and Strain of Case-Type Furniture Corner Joint, Proceedings of the 26th DAAAM International Symposium, pp.0391-0399, B. Katalinic (Ed.), Published by DAAAM International, ISBN 978-3-902734-07-5, ISSN 1726-9679, Vienna, Austria

DOI:10.2507/26th.daaam.proceedings.053 


\section{Introduction}

Case-type constructions are one of the most common products of the furniture industry. The strength and the stiffness structures of this type are predominantly determined by properties of joints. In order to find solution that would improve the properties of the dowel joints, and indirectly, to improve the resistance of structure during service, many affecting factors are analyzed [1, 2, 3, 4, 5]. Due to efficient technology, utilization of dowel joints is the most often way used to assemble wood panels or wood-based panels. The experimental investigations focus on the factors that affect the moment capacity [6, 7, 8]. Zhang and Eckelman have developed the expressions for estimating the bending strength as a function of number of dowels used, dowel diameter, and depth of insertion [8]. Although the expressions are limited to multi-dowel corner joints within the tested range, the authors have stated that depth of insertion has a much more effect then dowel diameter. The study [9] carried out using double-dowel corner joints with various configurations indicate that the strength of dowel joints becomes higher when the member's thicknesses and/or diameter of dowels are increased. It was determined that a greatest part of joints, $98 \%$, fails due to fracture of face member [9]. The investigation of joints produced by various wood based materials shows that the higher values of strength and stiffness are obtained for MDF joints than for PB joints and the highest values are obtained for PLY joints [10]. Failure load and optimum dowel spacing of joints, which are reinforced with glass-fibre fabric, are investigated by Yerlikaya $[11,12]$. Failure loads of reinforced joints are significantly higher than failure loads of unreinforced joints. The highest strength is obtained for $96 \mathrm{~mm}$ dowel spacing in LMDF joints, and for $128 \mathrm{~mm}$ dowel spacing in LPB joints. The studies $[13,14,15,16]$ provide descriptions of the numerical approaches to analyse properties of the furniture corner joints. The study [17] provides alternative methods of numerical rigidity modelling of dowel joints using nodes of substitute linear elasticity modulus that should be determined empirically. The stiffness values obtained by numerical analysis are compared with the experimental results in the study [10]. The difference reveals that the numerical results provide more rigid behaviour of joints. The normal stress patterns to contact planes on the edge one of the boards have been analyzed by the authors [18]. The stress value reached only the half-point of maximum values in the middle of the distance between fasteners.

\section{Research objective and methodology}

Some of the literature provides information on the influence dowel space on the corner joint strength. Generally, the maximum strength of joints (drilling module $\mathrm{m}=32 \mathrm{~mm}$ ) is obtained when the distance between the centers of dowel holes is not less than $96 \mathrm{~mm}[9,19]$. The critical distance of a dowel to the edge of a board is $50-60$ $\mathrm{mm}$. The failure mode analysis found that the weakest part of a dowel joint is the face member. Three types of joint failure that can occur are consequence of the position and the length of the fracture zone [9]. When the dowel spacing is less than $96 \mathrm{~mm}$, the fractures zones are overlapping, causing the reduction of joint strength, as opposed to instances where the zones are not overlapping. The expanded fracture zone reaches the edge of the face member when the distance between a dowel and the board edge is less than critical. Also, the joint resistance depends on the joint loading scheme [8]. In the case of compression loading, the joint strength is predominantly related to the internal bond strength of the board. In the case of tension loading, the joint strength is predominantly related to the tensile strength of the board. In contrast with the experimental studies, there are shorter articles available regarding the numerical analysis of the effect of dowel spacing on the joint properties.

The aim of this study is to investigate the applicability of numerical approach in case of determining the influence of dowel spacing on the mechanical properties of case-type furniture corner joints. Since the numerical calculation was limited to a linear elastic model for orthotropic material, the study presents the analysis of the qualitative aspect of stress and strain. The objective is to evaluate the effect of the distance between the centers of dowel holes, and the distance of a dowel to the edge of a board, on the distribution of the von Mises stress, and the distribution of translation displacement. Three significant dowel spacing were used in order to assess the differences between stress patterns, as well as displacement patterns, and the stiffness of the double-dowel corner joint subjected to compression or tension loads. Calculations were performed using the Catia software package.

\subsection{Mathematical model}

The stress and strain of a loaded solid body in static equilibrium are described by the equation of momentum balance, expressed in the Cartesian tensor notation [20],

$$
\int_{S} \sigma_{i j} n_{j} d S+\int_{V} f_{i} d V=0
$$

and the constitutive relation for elastic material

$$
\sigma_{i j}=C_{i j k l} \varepsilon_{k l}=\frac{1}{2} C_{i j k l}\left(\frac{\partial u_{k}}{\partial x_{l}}+\frac{\partial u_{l}}{\partial x_{k}}\right)
$$


In the equations above, $\mathrm{x}_{\mathrm{j}}$ are Cartesian spatial coordinates, $V$ is the volume of solution domain bounded by the surface $S, \sigma_{\mathrm{ij}}$ is the stress tensor, $n_{j}$ is the outward unit normal to the surface $S, f_{\mathrm{i}}$ is the volume force, $C_{i j k l}$ is the elastic constant of tensor components, $\varepsilon_{k l}$ is the strain tensor, and $u_{k}$ represents the point displacement. Twelve non-zero orthotropic elastic constants $A_{i j}$ are related to the Young's modulus $E_{i}$, the Poisson's ratio $v_{i j}$, and the shear modulus $G_{i j}$.

The mathematical model is complete when the boundary conditions are specified. Surface traction $f_{S i}$ and/or displacement $u_{S}$ at the domain boundaries are known, i.e.

$\sigma_{i j} n_{j}=f_{S_{i}}$ and $u_{i}=u_{S}$

Governing equations (1) combined with the constitutive relations (2) are solved with a numerical method based on the finite element.

General form of the von Mises stress can be expressed in terms of stress invariants $I_{l}$ and $I_{2}$

$$
\sigma_{V M}=\sqrt{I_{1}^{2}-3 I_{2}}
$$

\subsection{Physical model}

Double-dowel case-type furniture corner joint was selected for investigation. Geometries and measurements of the joint are shown in the Fig. 1.(a). The face member and the edge member of $18 \mathrm{~mm}$ in thickness were joined by two $50 \mathrm{~mm}$ long dowels with a $10 \mathrm{~mm}$ diameter, Fig. 1.(b). A symmetric half of the joint was taken for the solution domain, Fig. 1.(c). The dowel was fastened to the boards without glue line. The boards were contact-connected together as were the boards and the dowel ends. The face member was fixed at the lower end. Bending moment $M$ was applied to the end of the edge member. The imposed bending moment was $-10 \mathrm{Nm}$ (compression loading) and $10 \mathrm{Nm}$ (tension loading).

a

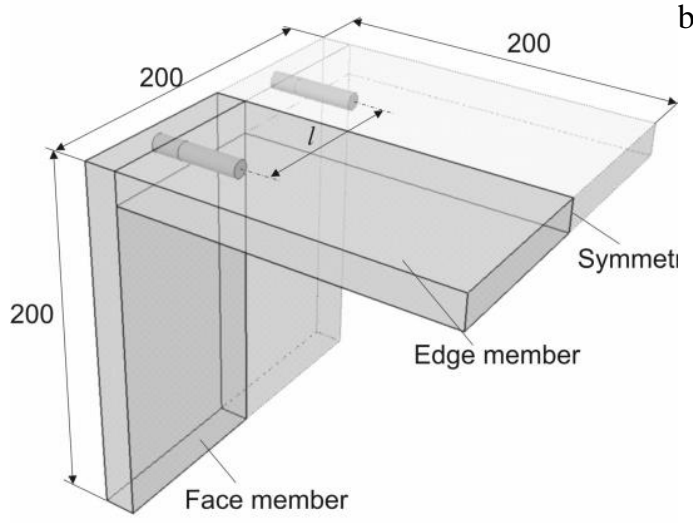

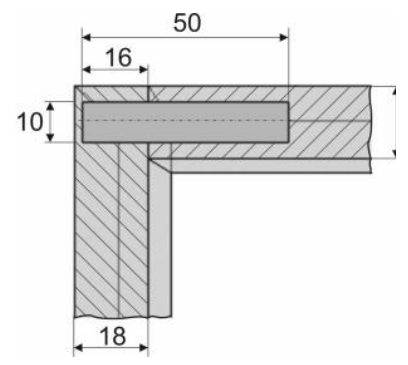

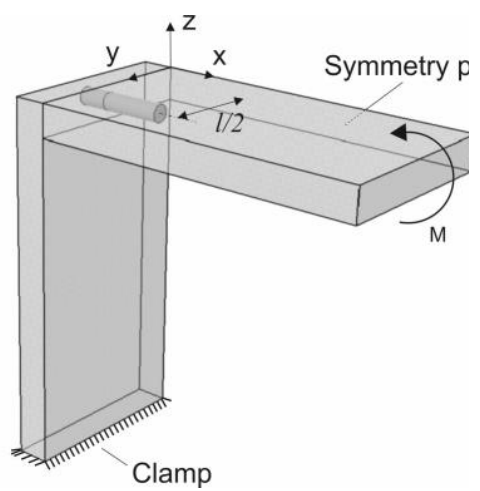

Fig. 1. (a) Dowel joint geometries; (b) configuration of the dowel; (c) joint loading scheme

Calculation was carried out for MDF boards. Its elastic properties, for board thickness of $18 \mathrm{~mm}$, density $\rho=0.787 \mathrm{~g} / \mathrm{cm}^{3}$ and internal bond strength of $0.55 \mathrm{MPa}$, are presented in Tab. 1 [18]. The dowel material was maple. Elastic properties of the maple wood, for wood density of $\rho=0.57 \mathrm{~g} / \mathrm{cm}^{3}$ and moisture content of $12 \%$, are presented in Tab. 1 [21]. Global and local coordinate systems were applied, and numerical calculations are carried out with a model for orthotropic material.

\begin{tabular}{|c|c|c|c|c|c|c|c|c|c|c|c|}
\hline \multicolumn{12}{|c|}{ MDF board } \\
\hline \multicolumn{3}{|c|}{ Modulus of elasticity $(\mathrm{GPa})$} & \multicolumn{3}{|c|}{ Rigidity modulus $(\mathrm{GPa})$} & \multicolumn{6}{|c|}{ Poisson's ratio } \\
\hline$E_{x}$ & $E_{y}$ & $E_{z}$ & $G_{x y}$ & $\mathrm{G}_{x z}$ & $\overline{G_{y z}}$ & \multicolumn{2}{|c|}{$v_{x y}$} & \multicolumn{2}{|c|}{$v_{x z}$} & \multicolumn{2}{|c|}{$v_{y z}$} \\
\hline 3.2 & 3.4 & 0.05 & 0.068 & 0.058 & 0.068 & \multicolumn{2}{|c|}{0.45} & & .50 & \multicolumn{2}{|c|}{0.50} \\
\hline \multicolumn{12}{|c|}{ Maple (Acer saccharum Marsh.). } \\
\hline \multicolumn{3}{|c|}{ Modulus of elasticity $(\mathrm{GPa})$} & \multicolumn{3}{|c|}{ Rigidity modulus $(\mathrm{GPa})$} & \multicolumn{6}{|c|}{ Poisson's ratio } \\
\hline$E_{L}$ & $E_{R}$ & $E_{T}$ & $G_{L R}$ & $\mathrm{G}_{L T}$ & $G_{R T}$ & $v_{L R}$ & $v_{L T}$ & $v_{R T}$ & $v_{T R}$ & $v_{R L}$ & $v_{T L}$ \\
\hline 13.810 & 1.311 & 0.678 & 1.013 & 0.753 & 0.255 & 0.46 & 0.50 & 0.82 & 0.42 & 0.044 & 0.025 \\
\hline
\end{tabular}

Table 1. Elastic properties of MDF board and maple dowel 
All measurements except dowel spacing $l$ were held constant. According to the furniture $32 \mathrm{~mm}$ system ( $\mathrm{m} \mathrm{x}$ $32 \mathrm{~mm}$ ), investigations were conducted on the corner joints with three different significant distances between dowels of $160 \mathrm{~mm}, 96 \mathrm{~mm}$ and 32mm, Fig. 2.

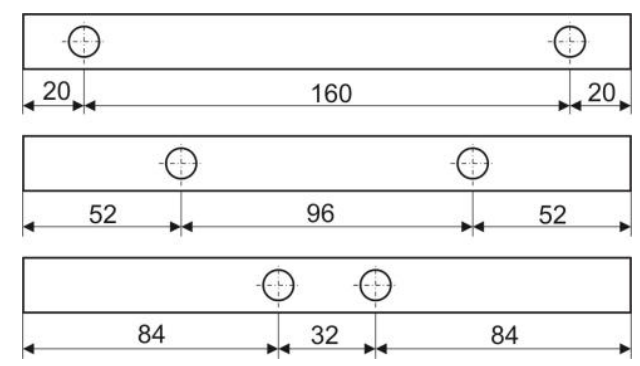

Fig. 2. Three distances between dowels

\section{Results}

The effect of dowel spacing on the von Mises stress patterns in the width directions of boards at the board surface planes was assessed. Positions of the selected width directions are shown in Fig. 3.

$\mathrm{a}$

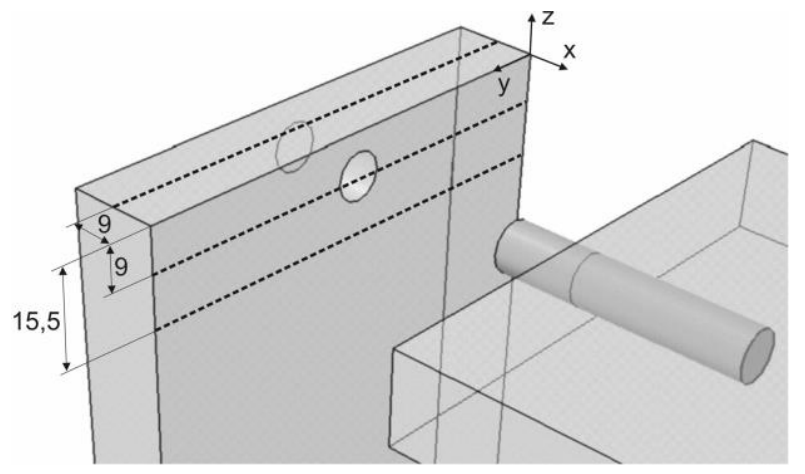

b

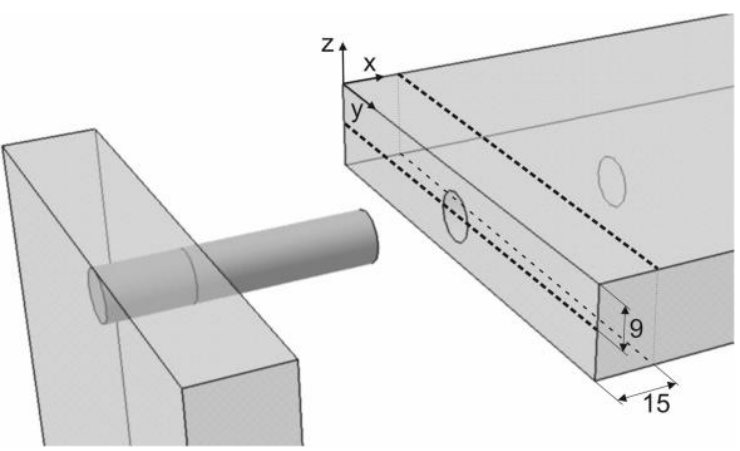

Fig. 3. Width directions: (a) face member, (b) edge member

The von Mises stresses along the board width on the plane thickness of face and edge members, and for compression and tension loadings, are presented in Fig. 4. and 5. Stress patterns vary significantly and indicate that the stress increases in the areas of the dowel. For the compression loading, the von Mises stress at the plane thickness of the face member is dominantly related to the tensile stress perpendicular to board plane. The dowel insertion affects the position of the stress that cause local board delamination. Fig 4.(a) showsthe areas where stress values are higher than the internal bond strength of the board $(0.55 \mathrm{MPa})$. The stress patternsof three dowel spacing correspond to fracture zones that occur during the fracture moment tests of dowel joints [9].For the tension loading, the edge of the face member is less significant due to the occurrence compression stress perpendicular to board plane, Fig. 4 (b).The high stress values in the edge member are the consequence of the local geometric and material discontinuity of the edge board weakened by the dowel holes. At the distance between dowels, and distance between dowels and the edges of the boards, stress values are lowerfor both cases of loadings, Fig 5.

a

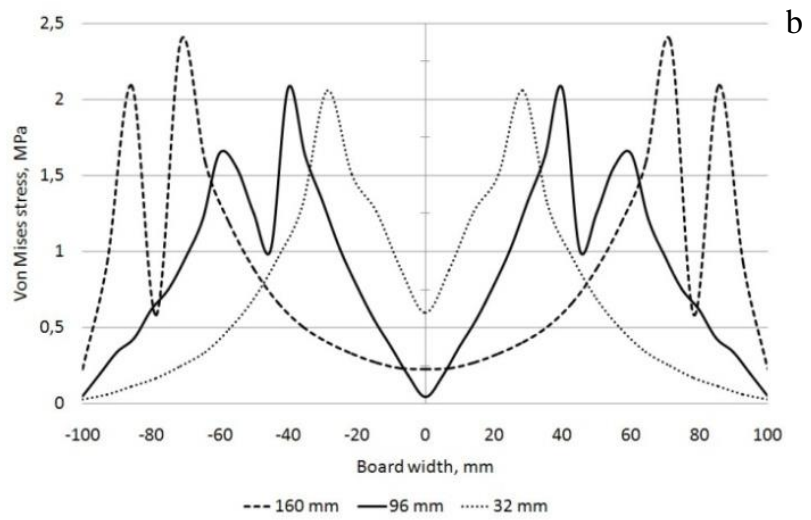

b

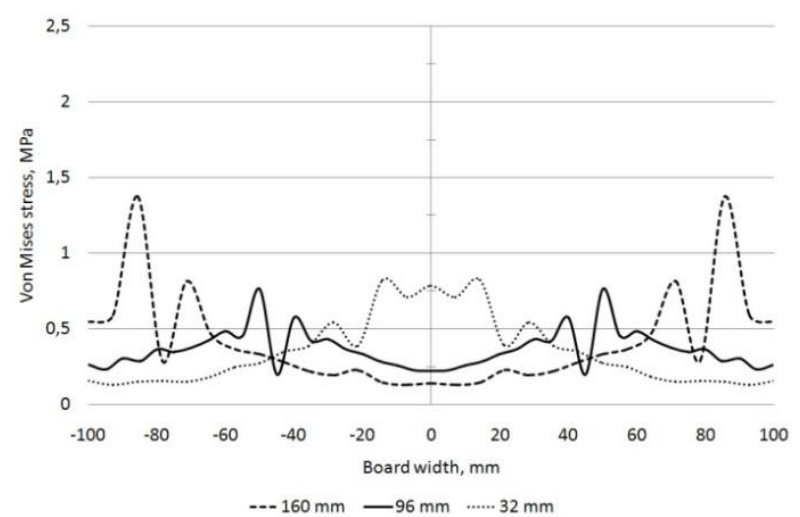

Fig. 4. The von Mises stress - face member (direction: $\mathrm{x}=-9 \mathrm{~mm}, \mathrm{z}=0$ ): (a) compression loading; (b) tension loading 
a

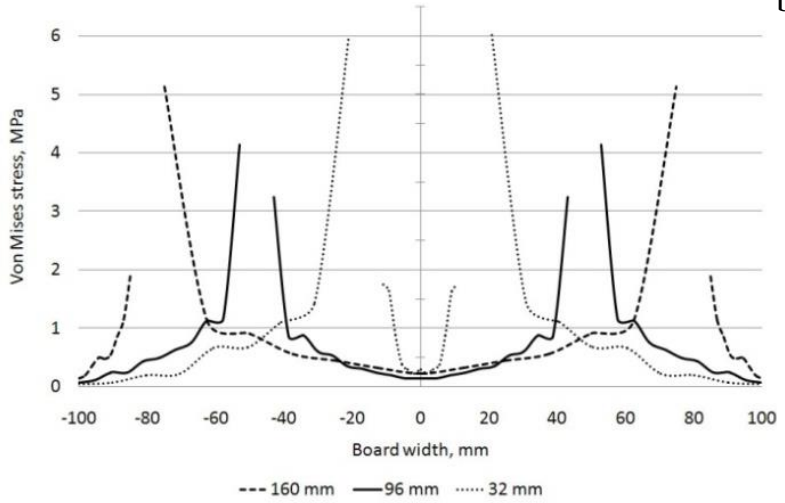

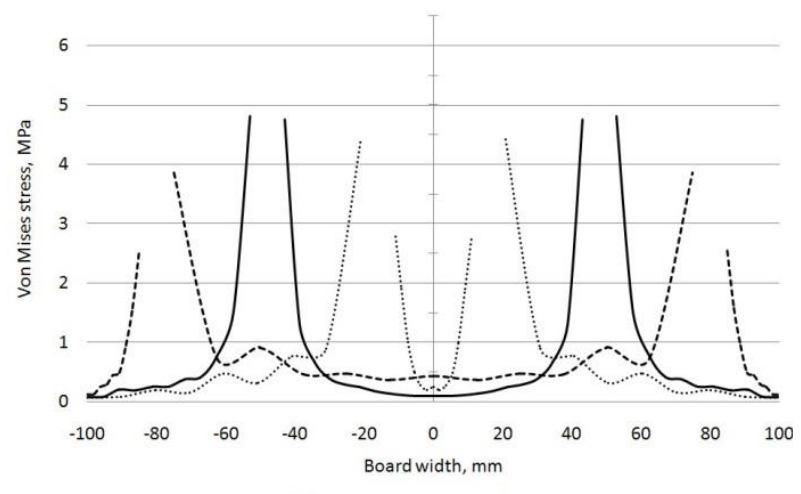

--- $160 \mathrm{~mm} \quad-96 \mathrm{~mm} \quad \ldots \ldots .32 \mathrm{~mm}$

Fig. 5. The von Mises stress - edge member (direction: $\mathrm{x}=0, \mathrm{z}=-9 \mathrm{~mm}$ ): (a) compression loading; (b) tension loading

The values of the von Mises stress along the other width directions, shown in Fig. 3., are higher and dominantly related to tensile and compression stress in the board planes. The stresses along the board width at the inner surface of face member, and for compression and tension loadings, are presented in Fig. 6. and 7. The von Mises stress along the board width, at the inner and outer surfaces of face member, and for compression and tension loadings, are presented in Fig. 8. and 9.

a

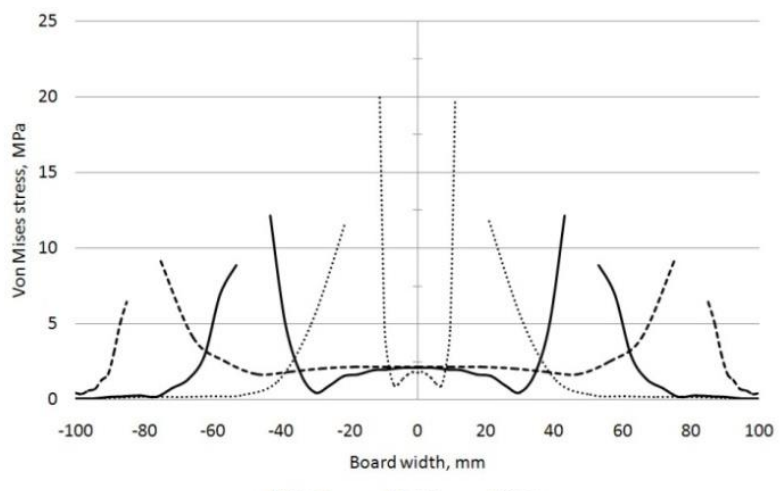

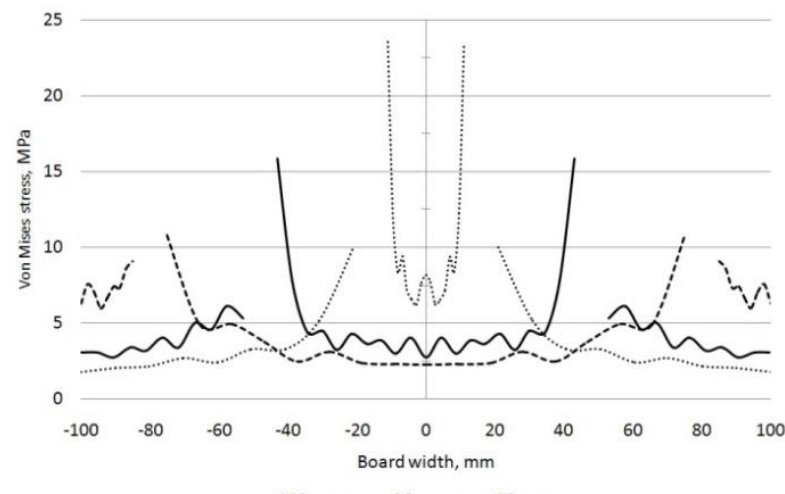

-.- $160 \mathrm{~mm} \quad-96 \mathrm{~mm} \quad \cdots . . .32 \mathrm{~mm}$

Fig. 6. The von Mises stress - face member (direction: $\mathrm{x}=0, \mathrm{z}=-9 \mathrm{~mm}$ ): (a) compression loading; (b) tension loading

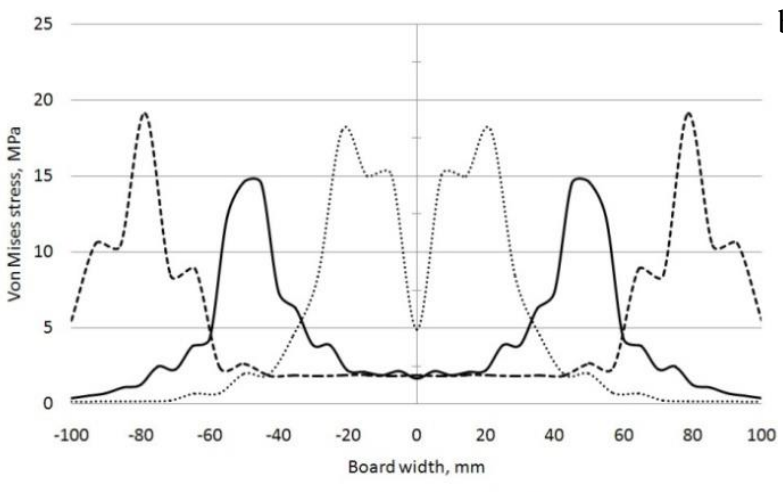

-.- $160 \mathrm{~mm} \quad-96 \mathrm{~mm} \quad \ldots . . .32 \mathrm{~mm}$

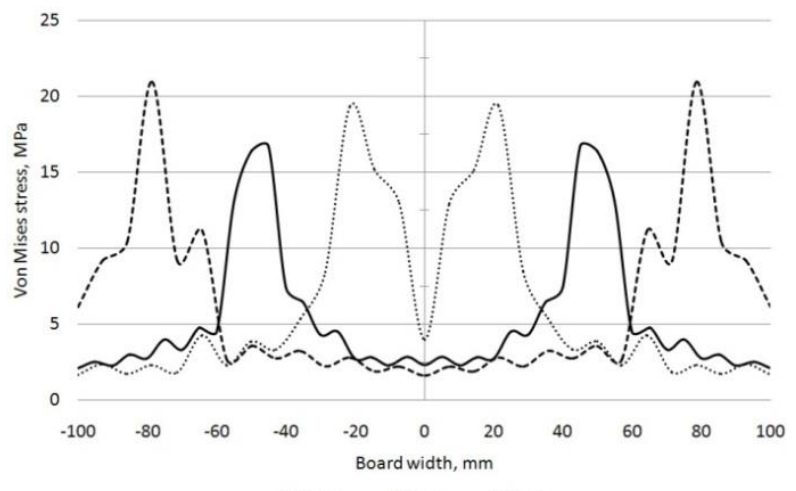

-.- $160 \mathrm{~mm} \quad-96 \mathrm{~mm} \quad \ldots . . .32 \mathrm{~mm}$

Fig. 7. The von Mises stress - face member (direction: $\mathrm{x}=0, \mathrm{z}=-15.5 \mathrm{~mm}$ ): (a) compression loading; (b) tension loading 


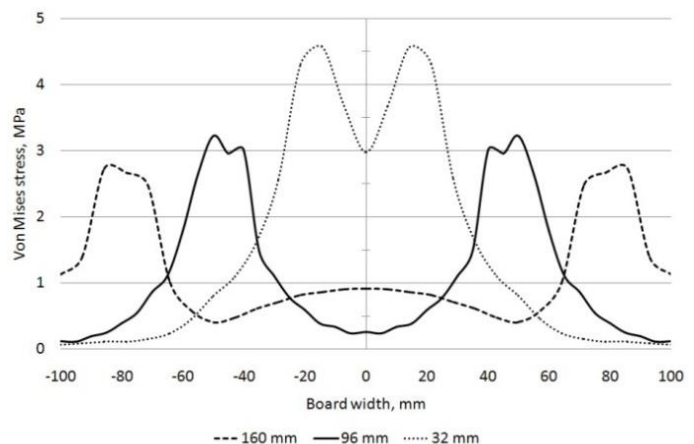

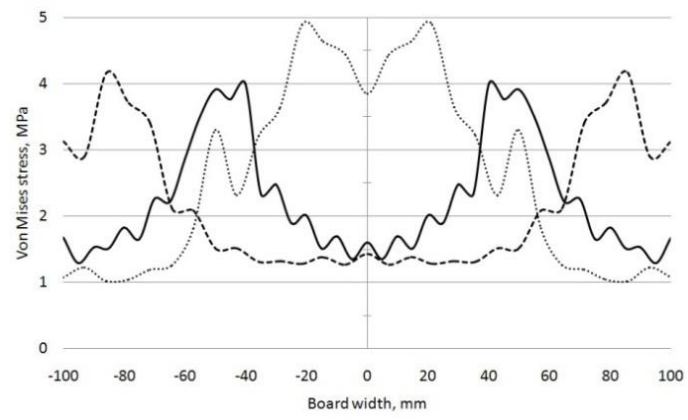

$--.160 \mathrm{~mm} \quad-96 \mathrm{~mm} \quad \ldots . . .32 \mathrm{~mm}$

Fig. 8. The von Mises stress - edge member (direction: $\mathrm{x}=15 \mathrm{~mm}, \mathrm{z}=0$ ): (a) compression loading; (b) tension loading

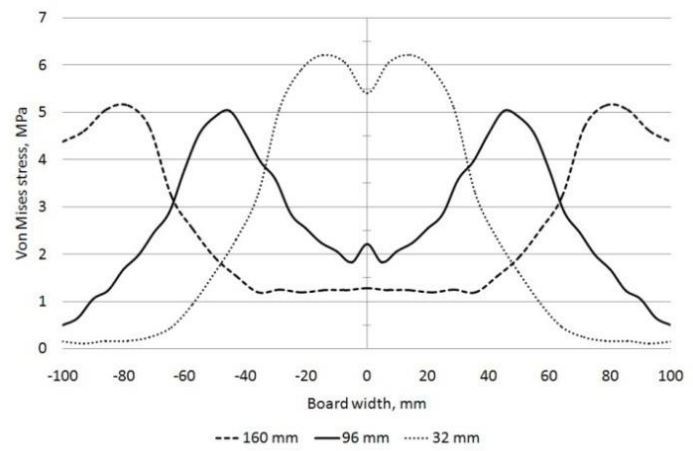

b

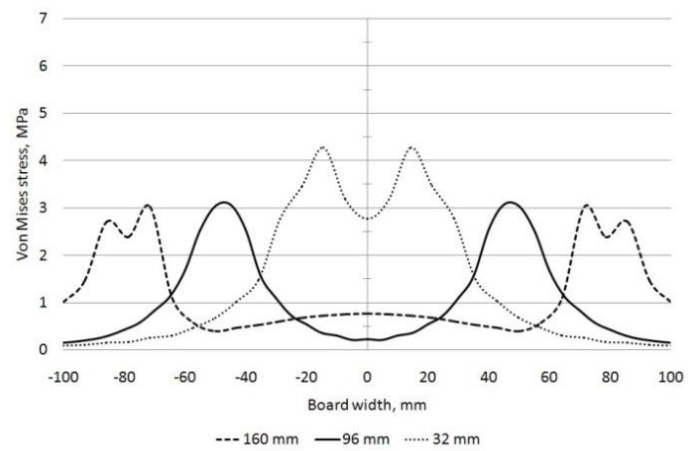

Fig. 9. The von Mises stress - edge member (direction: $x=15 \mathrm{~mm}, \mathrm{z}=-18 \mathrm{~mm}$ ): (a) compression loading; (b) tension loading

The stress patterns clearly indicate that dowel spacing affects the position and size of the high stress areas. The maximum values of the von Mises stress are obtained at the positions where dowels are inserted. The maximum values of stress are close to the MDF bending strength (MOR > $20 \mathrm{MPa}$ ) at the selected directions of the face member. For selected directions of the edge member, the maximum stresses are much lower. The effect of dowel spacing on the transition of the lower stress area between dowels is noticeable at allselected directions. When dowel spacing is $32 \mathrm{~mm}$, the lower stress area between dowels is minimal. The area of lower stress stretches and the length of the area are largest when dowel spacing is at $160 \mathrm{~mm}$. The effect of the dowel distance to the board edge on the von Mises stress is noticeable when the distance of a dowel to the board edge is $20 \mathrm{~mm}$, and dowel spacing is at $160 \mathrm{~mm}$. In that case, the areas of increased stress reach the board edges. The minimum stress values at the board edges are obtained when dowel spacing is at $32 \mathrm{~mm}$ and $96 \mathrm{~mm}$. The areas of lower stress between dowels and between the dowel and the board edge are obtained when distance between the centres of dowel holes is $96 \mathrm{~mm}$.

For compression loading, the results show that the maximum von Mises stress at the plane thickness of the face member is much higher than the internal bond strength of the board while the von Mises stress, dominantly related to the compression, at the inner surface of the face member is close to the surface strength of the board, Fig. 4.(a) and 7.(a). The inner surface of the face member is more significant in the case of tension loading, Fig. 6.(b) and 7.(b). The von Mises stress at the surface is dominantly related to the tensile stress, the maximum values of stress are higher, and the values of stress are increased at the edges of the face member, compared to the case of compressing loading. In that case, the maximum values of compression stress perpendicular to the face board are low, Fig 4.(b). As opposed to the face member, the values of stress at the surfaces of the edge member increase if the von Mises stress is dominantly related to the compression stress, Fig. 8. and 9.

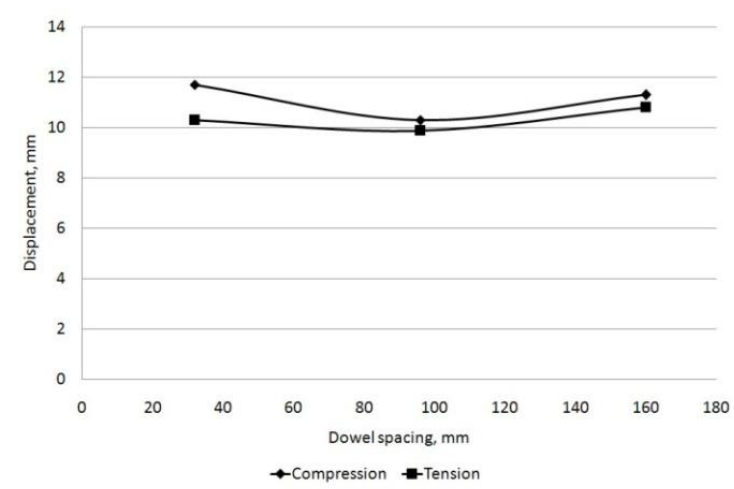

Fig. 10. Total translational displacement of the free end of the edge member: (a) compression loading; (b) tension loading 
The effect of dowel spacing on the total translational displacements of the free end of the edge member was assessed. Translational displacement and deformations of jointin cases of compression and tension loadings are shown in Fig. 10. and 11.

When the distance between the centers of dowel holes is $96 \mathrm{~mm}$, the joint stiffness is at maximum. By increasing the dowel spacing to $160 \mathrm{~mm}$, joint stiffness decreases by $\sim 8.5 \%$ for both cases of loadings. When the distance is $32 \mathrm{~mm}$, joint stiffness is decreased by $\sim 12 \%$ for case of compression loading and $\sim 4 \%$ for case of tension loading. Differences between displacement obtained for the compression and tension loadings range from $\sim 5 \%$ (distances: $160 \mathrm{~mm}$ and $96 \mathrm{~mm}$ ) to $14 \%$ (distance: $32 \mathrm{~mm}$ ).

a

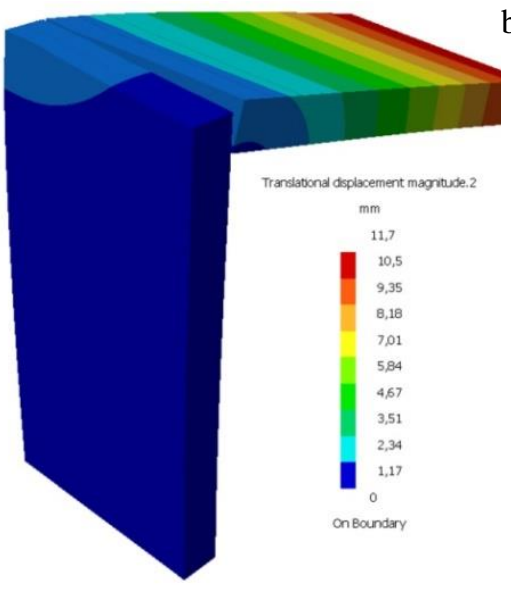

d

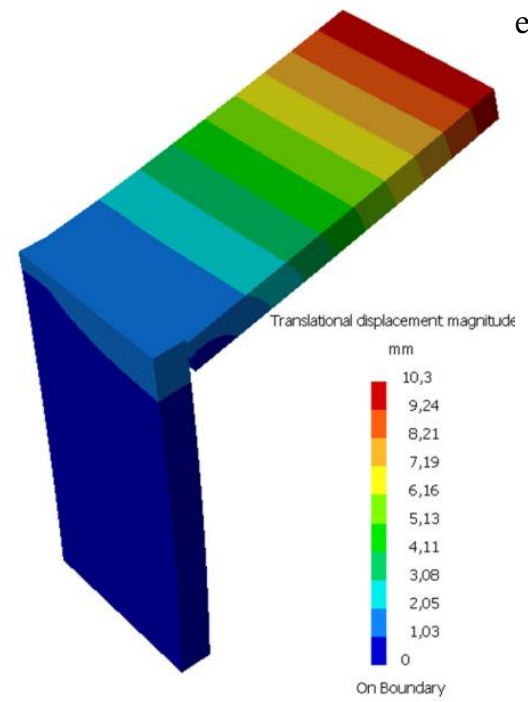

b
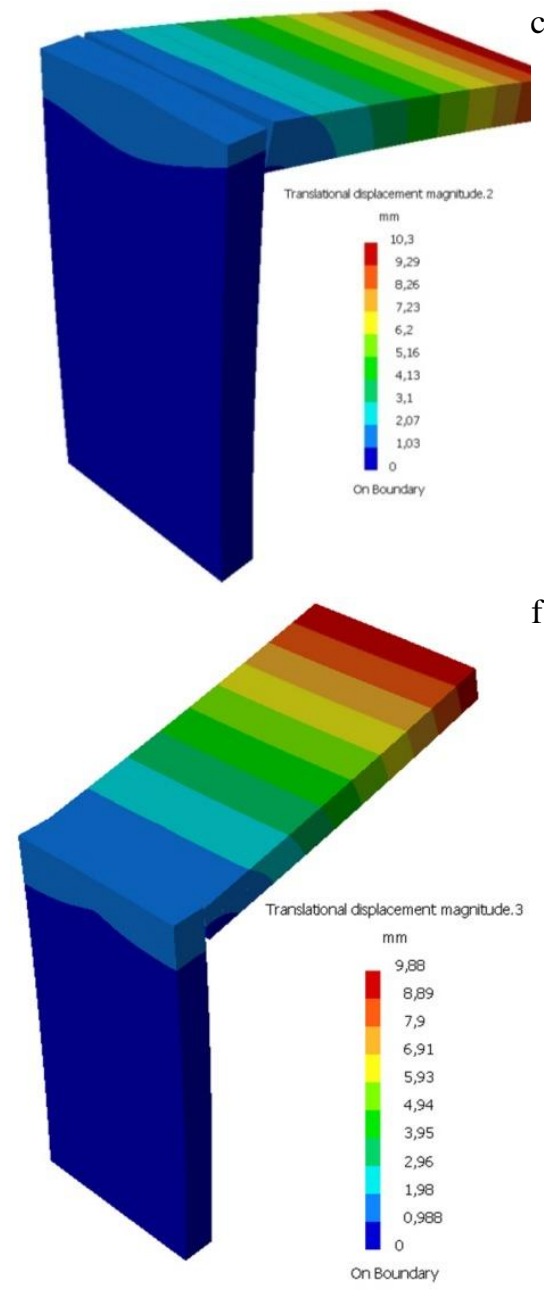

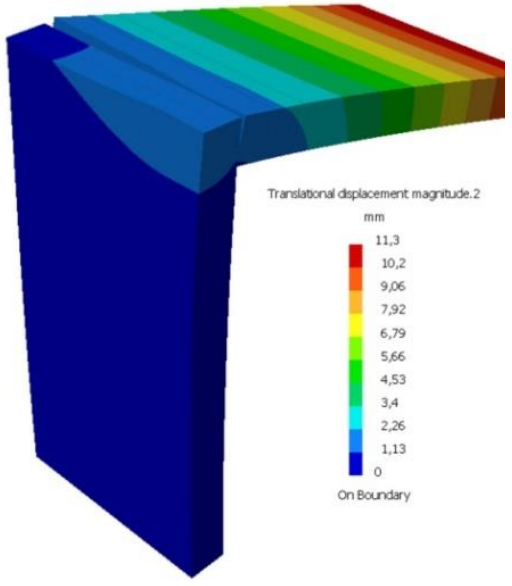

f

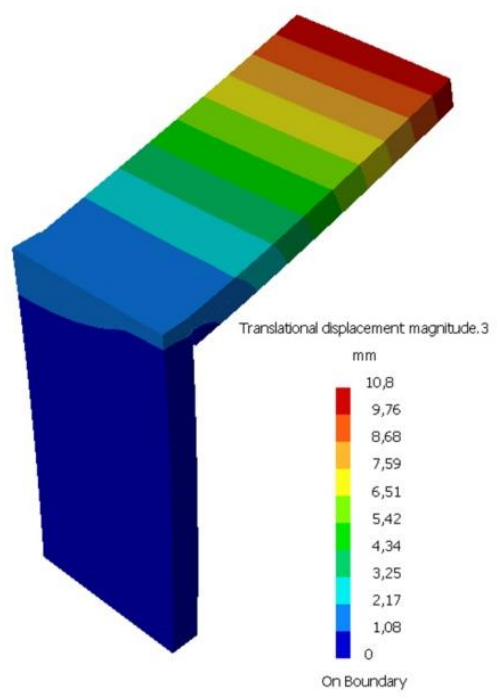

Fig. 11. Translational displacement and deformations of joint (scale 5:1). Compression loading - dowel spacing: (a) 32mm; (b) $96 \mathrm{~mm}$; (c) $160 \mathrm{~mm}$. Tension loading - dowel spacing: (d) 32mm; (e) $96 \mathrm{~mm}$; (f) $160 \mathrm{~mm}$

The effect of dowel spacing on displacement of the boards contact zone was obtained. The components of displacement along the board width at the outer surface edge (Fig. 3.(b); $x=0, z=0$ ) of the edge member, and for compression and tension loadings, are presented in Fig. 12. and 13. Compression loading of the joint caused a lack of contact between members on the selected edge. In the case of tension loading, contact stress occurred on the edge and reduced the displacement. Displacement differences due to applied cases of loading can be noticed at the $u$ component displacement patterns. The influence of dowel distance on the displacement is more noticeable at the $w$ component displacement patterns. When the distance between the centers of dowel holes is $96 \mathrm{~mm}$, the differences between displacements at the points along the width direction of the board are minimal and displacements are more uniform.

Generally, the numerical results indicate that the dowel spacing and the loading schemes influence the qualitative stress state and the strain in a similar way to the effect on the joint strength and stiffness obtained by experimental investigations $[8,9]$. 
a

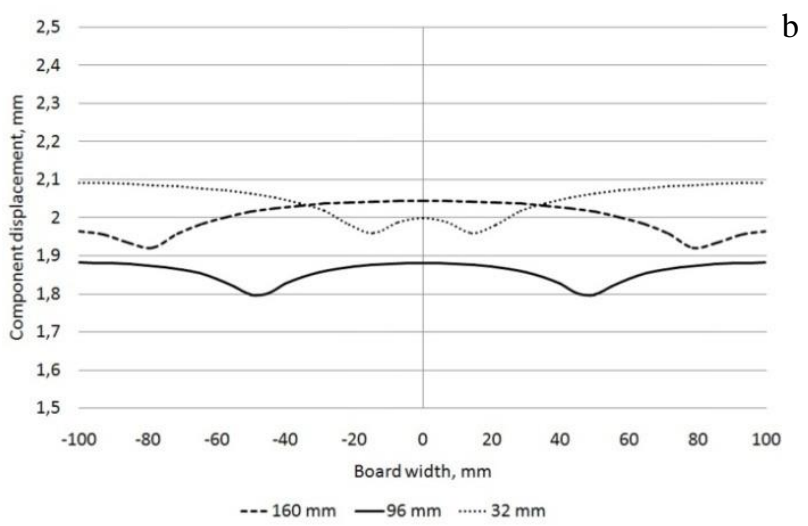

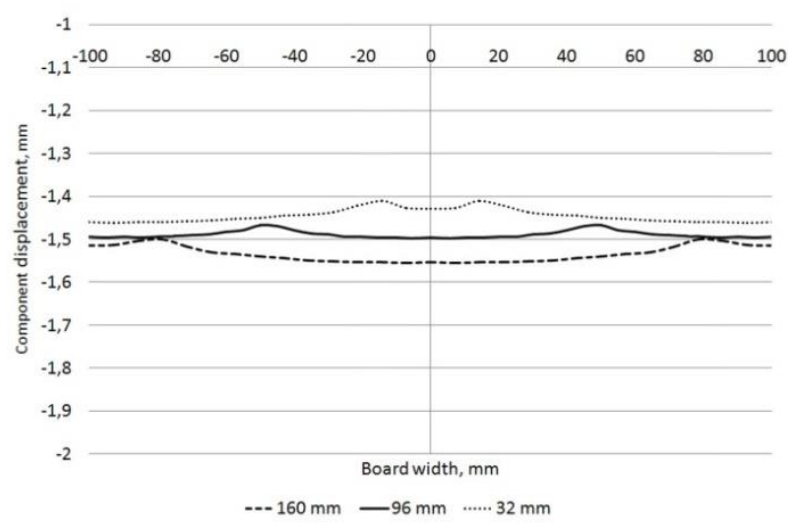

Fig. 12. Component displacement $\mathrm{u}$ - edge member (direction: $\mathrm{x}=0, \mathrm{z}=0$ ): (a) compression loading; (b) tension loading

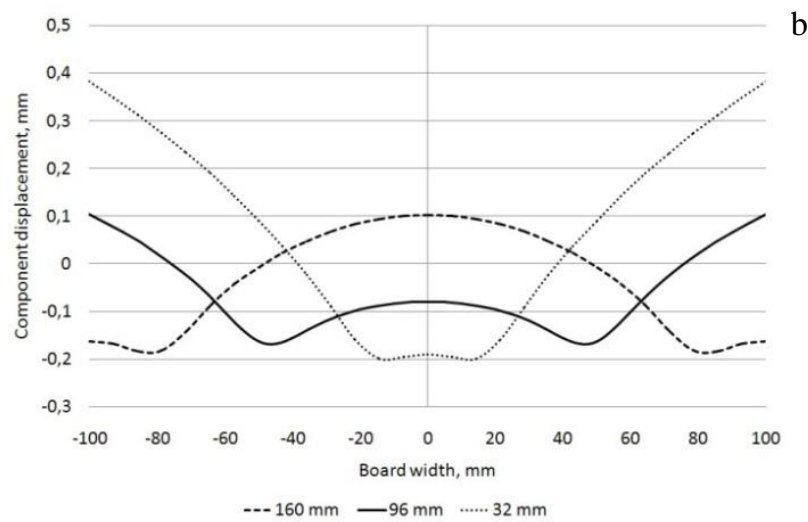

b

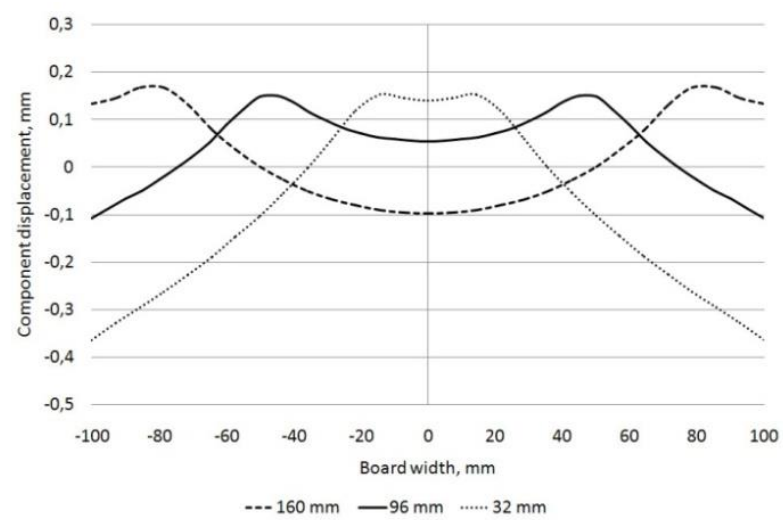

Fig. 13. Component displacement $\mathrm{w}$ - edge member (direction: $\mathrm{x}=0, \mathrm{z}=0$ ): (a) compression loading; (b) tension loading

\section{Conclusion}

The study was carried out in order to obtain information concerning the influence of three dowel positions of the loaded double-dowel corner joints on the qualitative features of the von Mises stress and strain.

The results indicate that dowel spacing has an effect on the stress patterns that correspond to the fracture zones of failure mode analysis. The joint with $96 \mathrm{~mm}$ dowel spacing has lover value of stress and/or the larger length of lower stress areas between the dowels, and between the dowels and the board edges than those with 32 and $160 \mathrm{~mm}$ dowel spacing. For joints with dowel spacing other than optimal, the results show increased stress between the dowels (dowel spacing: $32 \mathrm{~mm}$ ), or between the dowels and the board edges (dowel spacing: $160 \mathrm{~mm}$ ). The joint loading schemes influence the stress state at the analyzed directions. Particularly noticeable is the significance of the free edge of the face member of the compression loaded joint. For both loading schemes, the highest joint stiffness is obtained with $96 \mathrm{~mm}$ dowel spacing.

Future work will include consideration of the reinforced double-dowel corner joints. In addition, numerical analysis for elastic-plastic model is needed to assess the influence of dowel spacing on the stress and strain state of the corner joint.

\section{References}

[1] S. Prekrat, N. Španić, Scientific methods for determination of wooden corner joint designs, Drvna industrija, Vol. 60, No. 4 (2009) 245-251.

[2] K. Saar, J. Kers, Ü. Luga, A. Reiska, Detachable connecting fittings failure loads on plywood furniture, Proceedings of the Estonian Academy of Sciences, 64, 1S (2015) 113-117.

[3] J. Smardzewski, R. Klos, B. Fabisiak, Determination of the impact of creeping of furniture joints on their rigidity, Turkish Journal of Agriculture and Forestry, (2013) 37: 802 - 811.

[4] M. Yuksel, N. Yildirim, A. Kasal, Y.Z. Erdil, S. Demirci, Effect of the panel type and panel thickness on mement resistance of screw-jointed corner joints and stiffness of four-member cabinets, BioResources, 9(4), (2014) 63406349. 
[5] M. Šimek, E. Haviarova, C. Eckelman, The end distance effect of knockdown furniture fasteners on bending moment resistance of corner joints, Acta univ. agric. et silvic. Mendel. Brun., LVI, No. 2, (2008) 203-210.

[6] A. Malkoçoğlu, N. Ç. Yerlikaya, Ş. Özşahin, Evaluation and optimization of bending moment capacity of corner joints with different boring plans in cabinet construction, Wood research, 59 (1), (2014) 201-216.

[7] M. Dalvand, G. Ebrahimi, M. Tajvidi, M. Layeghi, Bending moment resistance of dowel corner joints in case-type furnitureunder diagonal compression load, Journal of Forestry Research, 25(4), (2014) 981-984.

[8] L. Zhang, C. A. Eckelman, Rational design of multi-dowel corner joints in case construction, Forest Product Journal, Vol.43 No. 11/12 (1993) 52-58.

[9] V. Norvydas, I. Juodeikiene, D. Minelga, The influence of glued dowel joints construction on the bending moment resistance, Materials science, Vol. 11 No. 1. (2005) 36-39.

[10] H. O. Imirzi, H. Efe, Analysis of strength of corner joints in cabinet type furniture by using finite element method, Proceedings of the XXVIth International Conference for Furniture Industry, September 19\&20, 2013 Poznan, Poland (2013) 49-55.

[11] N. C. Yerlikaya, Investigation of optimum dowel spacing for corner joints, which are reinforced with glass-fiber fabric in case-type furniture, Wood research, 59 (1) (2014) 191-200.

[12] N. C. Yerlikaya, Failure load of corner joints, which are reinforced with glass-fiber fabric in case-type furniture, Scientific Research and Essays Vol. 8(8) (2013) 325-339.

[13] N. Tankut, A.N. Tankut, M. Zor, Finite element analysis of wood materials, Drvna industrija, Vol. 65, No. 2 (2014) 159-171.

[14] S. Hajdarevic, S. Martinovic, Effect of tenon length on flexibility of mortise and tenon joint, 24th DAAAM International Symposium on Intelligent Manufacturing and Automation, 2013., Procedia Engineering, 69 (2014) 678-685.

[15] M. Šimek, P. Konas, Bending stress modeling of dismountable furniture joints applied with a use of finite element, Acta univ. agric. et silvic. Mendel. Brun., LVII, No. 1, (2009) 137-146.

[16] J. Zhou, C. Hu, S. Hu, H. Yun, G. Jaing, Optimization of hinge configuration of furniture doors using finite element analysis, , BioResources, 7(4), (2012) 5809-5816.

[17] J. Smardzewski, R. Klos, Modeling of joint substitutive rigidity of board elements, Annals of Warsaw University of Life Science, Forestry and Wood Technology No. 73 (2011) 7-15.

[18] R. Mostowski, M. Sydor, Contact FE-analysis of a furniture joint for various states of load, Proceedings of the 46th International Conference of Departments of Design of Machine Elements and Mechanisms, (2005) 228-231.

[19] A. N. Tankut, Optimum dowel spacing for corner joints in 32-mm cabinet construction, Forest Product Journal 55(12), (2005) 100-104.

[20] T. J. Chung, Applied continuum mechanics, Cambridge University Press, Cambridge, 1996.

[21] J. Boding, B. A. Jayne, Mechanics of wood and wood composites, Krieger publishing Company, Malabar Florida, 1993. 